\title{
Prevalence of work-aggravated symptoms in clinically established asthma
}

\author{
K. Saarinen*, A. Karjalainen", R. Martikainen\#, J. Uitti*, L. Tammilehto", T. Klaukka ${ }^{+}$, K. Kurppa ${ }^{\#}$
}

Prevalence of work-aggravated symptoms in clinically established asthma. K. Saarinen, A. Karjalainen, R. Martikainen, J. Uitti, L. Tammilehto, T. Klaukka, K. Kurppa. (C) ERS Journals Ltd 2003.

ABSTRACT: This population-based cross-sectional survey assessed the prevalence of work-aggravated asthma symptoms and the effect of the work environment on the aggravation of symptoms of established asthma.

A questionnaire was sent to 2,613 persons (aged 20-65 yrs) with asthma. The analyses were restricted to the 969 respondents who were currently employed. The effect of occupational exposure on the aggravation of asthma symptoms at work was assessed according to both self-reported and expert-evaluated exposure.

Approximately $21 \%$ of the respondents reported work-aggravated asthma symptoms at least weekly during the past month. The prevalence of those with work-aggravated symptoms increased by age, self-reported occupational exposure to dusts, abnormal temperatures or poor indoor air quality, physically strenuous work, and chemicals, and expert-evaluated probability of daily occupational exposure to airborne dusts, gases or fumes.

Aggravation of asthma symptoms at work is common among employed adults with asthma. Both self-reported and expert-evaluated exposure to dusts, abnormal temperatures or poor indoor air quality, physically strenuous work, and chemicals explained the significant worsening of symptoms. The findings suggest a marked role of the work environment in the aggravation of symptoms of established asthma.

Eur Respir J 2003; 22: 305-309.
*Tampere Regional Institute of Occupational Health and Clinic of Occupational Medicine, Tampere University Hospital, Tampere, ${ }^{\text {\# Dept }}$ of Epidemiology and Biostatistics, Finnish Institute of Occupational Health, Helsinki, Dept of Pulmonary Disease, Jorvi Hospital, Espoo, and ${ }^{+}$Social Insurance Institution, Helsinki, Finland.

Correspondence: K. Saarinen

Tampere Regional Institute of Occupational Health

PO Box 486

FIN-33101 Tampere

Finland

Fax: 35832608699

E-mail: kimmo.saarinen@ttl.fi

Keywords: Asthma

prevalence of work-aggravated symptoms work environment

Received: October 312002

Accepted after revision: March 282003
Asthma is a substantial health problem among people of working age and its prevalence appears to be increasing in many countries [1, 2]. Asthma is also a frequent cause of work disability [3].

Asthma in the workplace is usually separated into two categories: occupational asthma and work-aggravated asthma. Occupational asthma refers to cases caused by immunological sensitisation or initiated by a single high exposure to irritants. Work-aggravated asthma is pre-existing or concurrent asthma that is aggravated by irritants or physical stimuli in the workplace [4].

Only a few studies have addressed the prevalence of workaggravated asthma symptoms among patients with physiciandiagnosed asthma. TARLO et al. [5] reported that asthma was worse at work and was not worse on weekends or holidays from work for $16 \%$ of the workers with adult-onset asthma in a general asthma clinic population.

The aim of this survey was to assess the prevalence of work-aggravated asthma symptoms, and the effect of exposures and factors of the work environment on the aggravation of symptoms of established asthma. The study focused on asthma cases without any known occupational origin.

\section{Material and methods}

\section{Study population}

The study was a population-based cross-sectional survey. In October 2000, a questionnaire was sent to 2,613 asthmatics aged 20-65 yrs and living in the city of Tampere, Finland, at the end of 1997 (total population 190,000). The cases were identified from the Medication Reimbursement Register of the Finnish Social Insurance Institution. All those who had been granted special reimbursement rights for asthma medication at the end of 1997 and were alive in October 2000 were selected. Two reminders were sent and the response rate was $79 \%$.

To be granted reimbursement rights by the Finnish Social Insurance Institution, the disease must fulfil the diagnostic and severity criteria of asthma, including objective data of reversible bronchial obstruction and a typical and persistent pattern of disease (table 1). Among those granted special reimbursement rights for asthma medication, the reliability of the asthma diagnosis is high. In a random sample of workingaged asthmatics with granted reimbursement rights, clinically established asthma was present in $99 \%$ of subjects, but in $1 \%$ the reimbursement rights had been granted for other chronic pulmonary disease on the basis of a special individual assessment [6]. Therefore, in the current study, the respondents were asked whether or not they had asthma diagnosed by a physician. The $18(1 \%)$ without such a diagnosis and the 37 who did not reply to this question were excluded from the analyses. Patients with recognised occupational asthma do not receive reimbursement from the Social Insurance Institution but are fully compensated for asthma medication by the Statutory Accident Insurance system. Therefore, such patients were not included in the study.

There were $969(49 \%)$ respondents currently in full-time employment, $459(23 \%)$ had retired, $200(10 \%)$ were unemployed 
Table 1.-Diagnostic criteria for asthma granted special medication reimbursement from the Social Insurance Institution in Finland

A typical history, clinical features and course of asthma must be documented in the medical certificate, and the following physiological criteria are applied:

At least one of criteria 1-3:

1. a variation of $\geqslant 20 \%$ in PEF during a 24 -h period (reference to maximal value) or;

2. an increase of $\geqslant 15 \%$ in PEF or FEV1 with $\beta_{2}$-agonist or;

3. a decrease of $\geqslant 15 \%$ in PEF or FEV1 after exercise in exercise testing; and

4. a continuing regular use of asthma medication that has lasted for 6 months at the time of the decision

PEF: peak expiratory flow rate (in addition to the percentage limits given, an absolute change value of $\geqslant 50 \mathrm{~L} \cdot \mathrm{min}^{-1}$ is required); FEV1: forced expiratory volume in one second (in addition to the percentage limits given, an absolute change value of $\geqslant 0.15 \mathrm{~L}$ is required).

or had been made redundant and 297 (15\%) were currently outside of full-time working life due to other reasons (e.g. housewives, students, part-time workers, maternity leave, etc.). The analyses of this article were restricted to the 969 subjects who were currently in full-time employment. Onefifth of subjects worked in manufacturing and an equal number were employed in health and social work (table 2). At the time of the inquiry the subjects were aged 20-65 (mean 43.2) yrs. They had been diagnosed with asthma 4-52 (mean $17.5)$ yrs earlier. Altogether, $73 \%$ were aged $\geqslant 18$ yrs (adultonset) at the time of their asthma diagnosis (table 2). The

Table 2. - Distribution of the demographic and asthma characteristics of the 969 asthmatics employed full-time

\begin{tabular}{|c|c|c|c|}
\hline & Males & Females & All \\
\hline Subjects $n$ & 399 & 570 & 969 \\
\hline \multicolumn{4}{|l|}{ Age group yrs } \\
\hline $20-29$ & 13.8 & 9.5 & 11.2 \\
\hline $30-39$ & 31.2 & 24.0 & 26.9 \\
\hline $40-49$ & 26.9 & 30.9 & 29.2 \\
\hline $50-59$ & 24.4 & 33.2 & 29.5 \\
\hline$\geqslant 60$ & 3.8 & 2.5 & 3.0 \\
\hline \multicolumn{4}{|l|}{ Professional status } \\
\hline Self-employed & 14.3 & 6.9 & 10.0 \\
\hline Upper level nonmanual worker & 24.6 & 17.7 & 20.5 \\
\hline Lower level nonmanual worker & 18.3 & 37.3 & 29.5 \\
\hline Manual worker & 40.2 & 35.2 & 37.2 \\
\hline Other or unknown & 2.5 & 3.0 & 2.8 \\
\hline \multicolumn{4}{|l|}{ Onset of asthma } \\
\hline Child onset (<18 yrs) & 33.9 & 22.6 & 27.3 \\
\hline Adult onset ( $\geqslant 18$ yrs) & 66.1 & 77.4 & 72.7 \\
\hline \multicolumn{4}{|l|}{ Use of medication } \\
\hline Not at all & 11.1 & 10.7 & 10.9 \\
\hline Periodic & 35.2 & 28.7 & 31.4 \\
\hline Continuous & 53.8 & 60.6 & 57.8 \\
\hline \multicolumn{4}{|l|}{ Standard industrial classes } \\
\hline Manufacturing & 29.1 & 14.5 & 20.6 \\
\hline Health and social work & 3.8 & 30.5 & 19.5 \\
\hline $\begin{array}{l}\text { Wholesale and retail trade; repair of } \\
\text { motor vehicles, motorcycles and } \\
\text { personal and household goods }\end{array}$ & 14.3 & 9.0 & 11.1 \\
\hline $\begin{array}{l}\text { Real estate, renting and business } \\
\text { activities }\end{array}$ & 12.2 & 9.2 & 10.4 \\
\hline $\begin{array}{l}\text { Other community, social and } \\
\text { personal service activities }\end{array}$ & 7.1 & 9.0 & 8.2 \\
\hline $\begin{array}{l}\text { Transport, storage and } \\
\text { communications }\end{array}$ & 10.5 & 6.3 & 8.0 \\
\hline Education & 5.6 & 7.7 & 6.9 \\
\hline $\begin{array}{l}\text { Public administration and defence; } \\
\text { public social security }\end{array}$ & 4.6 & 7.0 & 6.0 \\
\hline Construction & 8.9 & 0.5 & 4.0 \\
\hline Hotels and restaurant & 0.5 & 3.2 & 2.1 \\
\hline Other & 3.3 & 3.1 & 3.2 \\
\hline
\end{tabular}

Data are presented as \%, unless otherwise stated. authors did not have any information on the employment status or other characteristics of the nonrespondents.

\section{Questionnaire}

The self-administered questionnaire included questions on personal characteristics, occupation, current exposures at work, aggravation of asthma symptoms at work, aggravation of asthma symptoms in general, use of medication and lifestyle.

\section{Exposure assessment}

In the analyses, the effect of occupational exposure on the aggravation of asthma symptoms at work was assessed according to both self-reported and expert-evaluated exposure.

Self-reported exposure. The respondents were asked about exposure to each of the following factors in their current job (yes, no, cannot say): dusts, chemical agents or factors, abnormal temperatures (cold or heat) or poor indoor air quality, mental stress, and physically strenuous work (high energetic demand).

Expert evaluation. The current occupation of the respondents was initially coded according to the 1997 Classification of Occupations of Statistics Finland [7], which is based on the International Standard Classification of Occupations, version 1988, used by the European Community, ISCO-88 (COM). The probability of nontrivial daily occupational exposure to dusts, fumes or gases in each occupation was thereafter classified as probable, possible or unlikely. The assessment was made by two experts familiar with occupational conditions (K. Saarinen, A. Karjalainen). The exposure was classified as probable for 237 occupations, possible for 200 occupations and unlikely for 188 occupations. Exposure was classified as probable for most manufacturing occupations, agricultural occupations and some service occupations (e.g. occupations related to cleaning and waste handling, and hairdressing). Exposure was classified as unlikely for office-type occupations, most teachers, most physicians and nurses, and most occupations in the human and social sciences. Exposure was classified as possible for most service, transport, sales and military occupations.

Smoking. According to the questionnaire data, the respondents were classified as current smokers, exsmokers, or nonsmokers.

\section{Assessment of work-related aggravation of asthma symptoms}

The respondents were asked about the average frequency of asthma symptoms caused or made worse by work during the 
last month and the last 12 months (not at all, less than once a week, one to two times a week, three to four times a week, daily or nearly daily). The frequencies were very similar for the last month and the past 12 months, and, to avoid bias caused by change of job or tasks, the authors performed the analyses according to the frequency of such symptoms during the last month.

\section{Statistical analyses}

The ordinal outcome variable was the frequency of asthma symptoms caused or made worse by work in the following four categories: not at all, less than weekly, one to two times a week, at least three times a week. Age (20-34, 35-44, 45-54, $\geqslant 55 \mathrm{yrs}$ ), sex, smoking, use of medication (less than daily, daily), onset of asthma (child, adult) and either self-reported or expert-evaluated exposure were included as explanatory variables. A proportional odds model was used to assess the effect of the explanatory variables on the ordinal outcome variable [8]. The validity of the proportional odds assumption was tested and the assumption that the estimated odds ratios (OR) were equal across all cut-off points dichotomising the outcome variable was applied. Interactions between the different self-reported occupational exposures were tested, but they were not significant and were not included in the model.

\section{Results}

Approximately $20 \%$ of the full-time workers reported work-aggravated asthma symptoms weekly during the past month and 19\% reported that such symptoms had occurred, but not weekly (table 3 ). The prevalence of those with

Table 3.-Distribution of the frequency of work-aggravated asthma symptoms during the last month according to age, sex, smoking, asthma severity and occupational exposure

\begin{tabular}{|c|c|c|c|c|c|c|}
\hline & \multirow{2}{*}{$\begin{array}{c}\text { Subjects } \\
\mathrm{n}\end{array}$} & \multicolumn{5}{|c|}{ Work aggravated symptoms } \\
\hline & & $\begin{array}{l}\text { Not } \\
\text { at all }\end{array}$ & $\begin{array}{l}\text { Less than } \\
\text { weekly }\end{array}$ & $\begin{array}{l}\text { 1-2 times } \\
\text { a week }\end{array}$ & $\begin{array}{l}\text { 3-4 times } \\
\text { a week }\end{array}$ & $\begin{array}{c}\text { Daily or } \\
\text { nearly daily }\end{array}$ \\
\hline All & 939 & 60.8 & 18.8 & 12.0 & 3.3 & 5.0 \\
\hline \multicolumn{7}{|l|}{ Age yrs } \\
\hline $20-34$ & 234 & 75.2 & 15.8 & 6.4 & 1.7 & 0.9 \\
\hline $35-44$ & 243 & 63.8 & 18.9 & 11.9 & 1.2 & 4.1 \\
\hline $45-54$ & 323 & 53.9 & 20.1 & 14.9 & 5.0 & 6.2 \\
\hline$\geqslant 55$ & 138 & 47.1 & 21.0 & 15.2 & 5.8 & 10.9 \\
\hline \multicolumn{7}{|l|}{ Sex } \\
\hline Male & 392 & 61.5 & 18.1 & 11.5 & 3.6 & 5.4 \\
\hline Female & 547 & 60.3 & 19.4 & 12.4 & 3.1 & 4.8 \\
\hline \multicolumn{7}{|l|}{ Smoking } \\
\hline Nonsmoker & 424 & 59.7 & 20.1 & 13.7 & 2.1 & 4.5 \\
\hline Exsmoker & 209 & 55.5 & 22.0 & 11.5 & 5.3 & 5.7 \\
\hline Smoker & 301 & 66.1 & 14.6 & 10.3 & 3.7 & 5.3 \\
\hline \multicolumn{7}{|c|}{ Use of medication during past 12 months } \\
\hline Not at all or periodic & 396 & 74.0 & 16.4 & 6.1 & 1.8 & 1.8 \\
\hline Continuous & 540 & 51.0 & 20.8 & 16.5 & 4.4 & 7.4 \\
\hline \multicolumn{7}{|l|}{ Onset of asthma } \\
\hline Child onset ( $<18$ yrs) & 256 & 74.6 & 14.8 & 8.2 & 1.2 & 1.2 \\
\hline Adult onset ( $\geqslant 18$ yrs) & 671 & 55.6 & 20.4 & 13.4 & 4.2 & 6.4 \\
\hline \multicolumn{7}{|c|}{ Self-reported occupational exposure } \\
\hline \multicolumn{7}{|c|}{ Dust } \\
\hline No & 232 & 86.6 & 9.1 & 3.0 & 0.4 & 0.9 \\
\hline Cannot say & 44 & 81.8 & 11.4 & 6.8 & 0.0 & 0.0 \\
\hline Yes & 631 & 49.6 & 23.5 & 15.9 & 4.3 & 6.8 \\
\hline \multicolumn{7}{|l|}{ Chemical agents } \\
\hline No & 459 & 74.3 & 13.3 & 8.7 & 1.7 & 2.0 \\
\hline Cannot say & 70 & 51.4 & 28.6 & 11.4 & 2.9 & 5.7 \\
\hline Yes & 338 & 47.3 & 24.3 & 14.8 & 5.3 & 8.3 \\
\hline \multicolumn{7}{|c|}{ Abnormal temperatures or bad indoor air quality } \\
\hline No & 289 & 81.7 & 11.8 & 5.2 & 1.4 & 0.0 \\
\hline Cannot say & 54 & 68.5 & 13.0 & 11.1 & 1.9 & 5.6 \\
\hline Yes & 554 & 49.1 & 23.3 & 15.5 & 4.3 & 7.8 \\
\hline \multicolumn{7}{|l|}{ Mental stress } \\
\hline No & 116 & 68.1 & 15.5 & 10.3 & 2.6 & 3.5 \\
\hline Cannot say & 54 & 57.4 & 16.7 & 14.8 & 7.4 & 3.7 \\
\hline Yes & 735 & 59.7 & 20.1 & 12.0 & 3.0 & 5.2 \\
\hline \multicolumn{7}{|c|}{ Physically strenuous work } \\
\hline No & 395 & 76.7 & 13.9 & 6.1 & 1.3 & 2.0 \\
\hline Cannot say & 38 & 57.9 & 15.8 & 18.4 & 5.3 & 2.6 \\
\hline Yes & 446 & 47.5 & 24.2 & 15.5 & 5.2 & 7.6 \\
\hline \multicolumn{7}{|c|}{ Probability of daily occupational exposure } \\
\hline Unlikely & 389 & 68.1 & 15.4 & 11.8 & 2.1 & 2.6 \\
\hline Possible & 325 & 56.9 & 23.7 & 11.4 & 4.0 & 4.0 \\
\hline Probable & 224 & 54.0 & 17.4 & 13.4 & 4.5 & 10.7 \\
\hline
\end{tabular}

Data are presented as \%. \#: job title-based probability of daily occupational exposure to airborne dusts, gases or fumes. 
work-aggravated symptoms increased by age and selfreported occupational exposure to dusts, abnormal temperatures or poor indoor air quality, physically strenuous work and chemicals, as well as by the expert-evaluated probability of daily occupational exposure to airborne dusts, gases or fumes. There was also an association between the prevalence of asthma symptoms and adult onset of asthma (table 3 ). The prevalence of work-aggravated symptoms was not affected much by the sex of the subject, smoking or occupational exposure to mental stress.

In the multivariable analysis, age, and self-reported exposure to dusts, abnormal temperatures or poor indoor air quality, physically strenuous work, and, to a lesser extent, chemicals were significant risk factors for work-aggravated asthma symptoms (table 4). Of the occupational exposures, exposure to dusts was associated with the highest risk $(\mathrm{OR}=3.1$, $95 \%$ confidence interval $=1.9-4.9)$. When the expert-evaluated probability of occupational exposure to dusts, gases or fumes was used as a marker of occupational exposure (instead of self-reported exposures), age and the probability of occupational exposure were significant predictors of work-aggravated asthma symptoms. A two-fold risk was associated with probable exposure in comparison with unlikely exposure (table 4). The outcome variable was frequency of workaggravated asthma symptoms (not at all, less than weekly, one to two times a week, at least three times a week). The proportional odds test indicated that the ORs were equal across all cut-off points dichotomising the outcome variable. The frequencies of symptoms in table 3 indicate that the ORs would have been clearly higher if only the extremes of the outcome variable (not at all versus at least three times a week) had been used. As there were no interactions between the different self-reported occupational exposures, the ORs of the multiple exposures can be estimated by multiplying the respective ORs.

In a separate question, the study addressed whether the frequency or severity of the asthma symptoms was greater during a period at work or during leisure time. Among the 191 with weekly work-aggravated symptoms, there were 47 respondents who reported work-aggravated asthma symptoms daily or almost daily. Some $83 \%(n=39)$ of these persons also reported that they had more often and/or more severe asthma symptoms at work than during leisure time.

\section{Discussion}

The results of this study indicate that the aggravation of asthma symptoms at work is common among employed adults with asthma, especially those with adult-onset asthma. Self-reported or expert-evaluated exposure to dusts, chemicals and physically strenuous work significantly explained the worsening.

The case ascertainment was done through a national registry that relies on diagnoses made by chest physicians on the basis of clinical and physiological criteria, and the presence of a persistent form of asthma. The authors were interested in the aggravation of established asthma at work and, therefore, workers with a clinical history of permanent asthma were ideal subjects for the study. The study population did not include occupational asthma cases defined by Finnish legislation. The response rate was sufficiently high, but information on the nonrespondents' employment status or their characteristics was not available.

In the current study, $20 \%$ of the full-time workers reported work-aggravated asthma symptoms weekly during the past month. In a study comparing the characteristics of patients with occupational and nonoccupational asthma, British researchers reported that $31 \%$ of the patients with
Table 4.-Multivariable model of risk of work-aggravated asthma symptoms by age, sex, smoking and self-reported (model 1) or expert-evaluated (model 2) occupational exposure in current job

\begin{tabular}{|c|c|c|}
\hline Risk factor & Model 1 & Model 2 \\
\hline \multicolumn{3}{|l|}{ Age yrs } \\
\hline $20-34$ & $1.0 \mathrm{ref}$ & $1.0 \mathrm{ref}$ \\
\hline $35-44$ & $1.4(0.9-2.3)$ & $1.5(1.0-2.3)$ \\
\hline $45-54$ & $1.6(1.0-2.6)$ & $1.8(1.2-2.8)$ \\
\hline$\geqslant 55$ & $1.7(1.0-3.0)$ & $2.1(1.3-3.4)$ \\
\hline \multicolumn{3}{|l|}{ Sex } \\
\hline Male & $1.0 \mathrm{ref}$ & $1.0 \mathrm{ref}$ \\
\hline Female & $0.9(0.6-1.2)$ & $1.0(0.7-1.3)$ \\
\hline \multicolumn{3}{|l|}{ Smoking } \\
\hline Nonsmoker & $1.0 \mathrm{ref}$ & $1.0 \mathrm{ref}$ \\
\hline Exsmoker & $1.0(0.7-1.4)$ & $1.0(0.7-1.4)$ \\
\hline Smoker & $0.9(0.6-1.3)$ & $0.9(0.7-1.3)$ \\
\hline \multicolumn{3}{|c|}{$\begin{array}{l}\text { Use of medication during past } \\
12 \text { months }\end{array}$} \\
\hline Not at all or periodic & $1.0 \mathrm{ref}$ & $1.0 \mathrm{ref}$ \\
\hline Continuous & $2.9(2.1-4.1)$ & $2.5(1.9-3.3)$ \\
\hline \multicolumn{3}{|l|}{ Onset of asthma } \\
\hline Child onset (<18 yrs) & $1.0 \mathrm{ref}$ & $1.0 \mathrm{ref}$ \\
\hline Adult onset ( $\geqslant 18 \mathrm{yrs})$ & $1.6(1.1-2.3)$ & $1.6(1.1-2.4)$ \\
\hline \multicolumn{3}{|l|}{$\begin{array}{l}\text { Self-reported occupational } \\
\text { exposure }\end{array}$} \\
\hline \multicolumn{3}{|l|}{ Dusts } \\
\hline No & $1.0 \mathrm{ref}$ & \\
\hline Cannot say & $1.1(0.4-2.8)$ & \\
\hline Yes & $3.1(1.9-4.9)$ & \\
\hline \multicolumn{3}{|l|}{ Chemicals } \\
\hline No & $1.0 \mathrm{ref}$ & \\
\hline Cannot say & $1.3(0.8-2.4)$ & \\
\hline Yes & $1.5(1.1-2.2)$ & \\
\hline \multicolumn{3}{|l|}{$\begin{array}{l}\text { Abnormal temperatures or } \\
\text { bad indoor air quality }\end{array}$} \\
\hline No & $1.0 \mathrm{ref}$ & \\
\hline Cannot say & $1.3(0.6-2.6)$ & \\
\hline Yes & $2.2(1.5-3.2)$ & \\
\hline \multicolumn{3}{|l|}{ Mental stress } \\
\hline No & $1.0 \mathrm{ref}$ & \\
\hline Cannot say & $1.2(0.6-2.5)$ & \\
\hline Yes & $1.2(0.8-2.0)$ & \\
\hline \multicolumn{3}{|c|}{ Physically strenuous work } \\
\hline No & $1.0 \mathrm{ref}$ & \\
\hline Cannot say & $1.9(0.9-4.2)$ & \\
\hline Yes & $2.0(1.4-2.8)$ & \\
\hline \multicolumn{3}{|c|}{$\begin{array}{l}\text { Probability of daily occupational } \\
\text { exposure }\end{array}$} \\
\hline Unlikely & & $1.0 \mathrm{ref}$ \\
\hline Possible & & $1.5(1.1-2.1)$ \\
\hline Probable & & $2.0(1.4-2.8)$ \\
\hline
\end{tabular}

Data are presented as odds ratio (95\% confidence interval). Ref: reference number. ${ }^{\#}$ : job title-based probability of daily occupational exposure to airborne dusts, gases or fumes.

nonoccupational asthma claimed that their asthma symptoms worsened during the weekdays, however, the study population was only small $(n=29)$ [9]. In a community sample of adults with asthma, the prevalence of respiratory symptoms at work was $\sim 20 \%$ [10]. However, since a majority of the patients did not have diagnosed asthma, the study was concerned with the prevalence of different respiratory symptoms, not the aggravation of established asthma at work.

In a study of asthma cases from a pulmonary clinic, by TARLO et al. [5], 16\% of the workers with adult-onset asthma reported their asthma to be worse at work. Altogether, 16 of these patients $(31 \%)$ had likely or possible sensitiser-induced occupational asthma and underlying asthma was probably 
aggravated in $49 \%$. The other $20 \%$ of the patients had possible occupational asthma or an aggravation of underlying asthma at work. TARLO et al. [5] did not assess the frequency of symptoms. In a survey by ARIF et al. [11], the prevalence of medically diagnosed asthma was $9.7 \%$ and the prevalence of work-related asthma was $3.7 \%$. The authors' definition of work-related asthma was taken from positive responses to the following two questions: "Has a doctor ever told you that you had asthma?" and "Are any of the symptoms wheezing, whistling, stuffy, itchy, or runny nose, watery, itchy eyes brought on by work environment?" [11]. The authors did not find any study with a design resembling that of the current study, consisting of clinically diagnosed asthma cases, which would have assessed the frequency of work-related symptoms. Exposure at the workplace may cause further impairment of currently symptomatic asthma or it may trigger a relapse of pre-existing asthma. This issue is of great clinical relevance, but the literature addressing this topic is scant [12].

The design and target population in the current study include some features that must be borne in mind when the results of the study are interpreted. A comparison group of nonasthmatic adults was not used in this study, as the authors wanted to study work-aggravation of symptoms of established asthma. This approach may have led to an overestimate of the problem, since all the work-aggravated symptoms of the respondents were not necessarily due to their asthma. Awareness of a dusty working environment may influence the response of an individual with respect to a causal association (i.e. somebody working in a dusty environment may be more likely to report aggravation of asthma symptoms). The symptoms are always subjective and such a recall bias is hard to avoid. Conversely, only people in full-time employment were studied and questions were focused on their current occupation. Therefore, work-related aggravation that had already led to a discontinuation of work or a change of job was unaccounted for. This underestimates the problem. Such situations are likely to be the most severe consequences of work-aggravated asthma. Finally, the authors wish to emphasise that the aetiology of new-onset asthma was not studied. It is possible that, for some subjects, aggravating factors may have also played a role in the inception of asthma but, for many, these factors were completely unrelated to the aetiology and any conclusions in this respect cannot be drawn.

Exposure to dust and chemicals proved to be significant risk factor for work-aggravated asthma symptoms. These exposures have also been shown to increase the risk of asthma [13-15]. The studies in question, contrary to the current study, were mostly concerned with the aetiological factors of asthma, but it has been impossible to differentiate symptom aggravation from causative effects. In addition to sensitisation (e.g. mediated by immunoglobulin E), other causative mechanisms for occupational or work-related asthma are irritantinduced or sensitisation occurring through unknown mechanisms [4]. Some of these cases are not diagnosed as occupational asthma. It is possible that, in the current study population, some of the asthma cases had been caused by these specific work-related factors. However, it is likely that this problem concerns only a small number of subjects, since the focus was mainly on the aggravation of symptoms of established asthma.

There is a lack of studies on the effects of age and smoking on the frequency of asthma symptoms. In the current study, age seemed to increase the frequency of symptoms aggravated by work. There are no data on the duration of exposure at work, and therefore no association could be made between age and duration of exposure. In the current study, smoking did not affect the frequency of asthma symptoms aggravated by work.

Surprisingly, few studies have been conducted on the symptoms of asthmatics at work. The comparison of these studies is difficult because of the differing definitions of asthma, the differing exclusion criteria and the differing concepts of the work-relatedness of asthma. The focus of other studies has been more directed at the aetiological factors inducing asthma. The findings from the current study support the assumption that the work environment plays an important role in the aggravation of symptoms of established asthma. Measures for tertiary prevention are needed at the workplace.

\section{References}

1. Sears MR. Descriptive epidemiology of asthma. Lancet 1997; 350: Suppl. 2, 1-4.

2. Woodruff PG, Fahy LV. Asthma: prevalence, pathogenesis, and prospects for novel therapies. JAMA 2001; 286: 395-398.

3. Blanc PD, Cisternas M, Smith S, Yelin EH. Asthma, employment status, and disability among adults treated by pulmonary and allergy specialists. Chest 1996; 109: 688-696.

4. Chan-Yeung M, Malo JL. Occupational asthma. $N$ Eng J Med 1995; 333: 107-112.

5. Tarlo SM, Leung K, Broder I, Silverman F, Holness DL. Asthmatic subjects symptomatically worse at work-prevalence and characterization among a general asthma clinic population. Chest 2000; 118: 1309-1314.

6. Karjalainen A, Kurppa K, Martikainen R, Klaukka T, Karjalainen J. Work is related to substantial portion of adult-onset asthma incidence in the Finnish population. Am J Respir Crit Care Med 2001; 164: 565-568.

7. Tilastokeskus Ammattiluokitus 1997. [Classification of occupations 1997]. Käsikirjoja 14 [Handbook 14]. Helsinki, Statistics Finland, 1997.

8. McCullagh P, Nelder JA. Generalized linear models, 2nd Edn. London, Chapman Hall, 1989.

9. Axon EJ, Beach JR, Burge PS. A comparison of some of the characteristics of patients with occupational and nonoccupational asthma. Occup Med 1995; 45: 109-111.

10. Abramson MJ, Kutin JJ, Rosier MJ, Bowes G. Morbidity, medication and trigger factors in a community sample of adults with asthma. Med J Aust 1995; 162: 78-81.

11. Arif AA, Whitehead LW, Delclos GL, Tortolero SR, Lee ES. Prevalence and risk factors of work related asthma by industry among United States workers: data from the third national health and nutrition examination survey (1988-94). Occup Environ Med 2002; 59: 505-511.

12. Toren K, Brisman J, Olin A-C, Blanc PD. Asthma on the job: work-related factors in new-onset asthma and in exacerbations of pre-existing asthma. Respir Med 2000; 94: $529-535$.

13. Toren K, Balder B, Brisman J, et al. The risk of asthma in relation to occupational exposures: a case-control study from a Swedish city. Eur Respir J 1999; 13: 496-501.

14. Toren K, Järvholm B, Brisman J, Hagberg S, Hermansson B-A, Lillienberg L. Adult-onset asthma and occupational exposures. Scand J Work Environ Health 1999; 25: 430-435.

15. Flodin U, Ziegler J, Jönsson P, Axelson O. Bronchial asthma and air pollution at workplaces. Scand $J$ Work Environ Health 1996; 22: 451-456. 